\title{
Repair of arch hypoplasia and ventricular septal defect in unseparated, pyopagus conjoined twins
}

\author{
Tracy R. Geoffrion, MD, MPH, ${ }^{a}$ Chitra Ravishankar, MD, ${ }^{\mathrm{b}}$ Aaron T. Dorfman, MD, ${ }^{\mathrm{b}}$ \\ Lisa M. Montenegro, MD, ${ }^{\mathrm{c}}$ Susan C. Nicolson, MD, ${ }^{\mathrm{c}}$ and Christopher E. Mascio, MD, ${ }^{\text {a }}$ Philadelphia, Pa
}

\footnotetext{
From the Divisions of ${ }^{\mathrm{a} C a r d i o t h o r a c i c ~ S u r g e r y, ~}{ }^{\mathrm{b}}$ Cardiology, and ${ }^{\mathrm{c}}$ Cardiothoracic Anesthesiology, Children's Hospital of Philadelphia, Philadelphia, $\mathrm{Pa}$.

Disclosures: Dr Mascio is a clinical consultant for HeartWare/Medtronic. All other authors reported no conflicts of interest.

The Journal policy requires editors and reviewers to disclose conflicts of interest and to decline handling or reviewing manuscripts for which they may have a conflict of interest. The editors and reviewers of this article have no conflicts of interest.

Received for publication March 13, 2020; revisions received March 13, 2020; accepted for publication April 2, 2020; available ahead of print April 11, 2020.

Address for reprints: Tracy Geoffrion, MD, MPH, The Cardiac Center, Children's Hospital of Philadelphia, 3401 Civic Center Blvd, Suite 8574, Philadelphia, PA 19104 (E-mail: geoffriont@email.chop.edu).

JTCVS Techniques 2020;3:300-2

2666-2507

Copyright (C 2020 The Authors. Published by Elsevier Inc. on behalf of The American Association for Thoracic Surgery. This is an open access article under the CC BY-NC-ND license (http://creativecommons.org/licenses/bync-nd/4.0/).

https://doi.org/10.1016/j.xjtc.2020.04.005
}

Previous reports of cardiac surgery in conjoined twins describe using no circulatory support or circulatory support on a single unseparated twin and operations on previously separated twins. ${ }^{1-3}$ This is the first report of operating on unseparated twins using circulatory support for both neonates.

\section{CASE SUMMARY}

The patients were 13-day-old $5.2 \mathrm{~kg}$ twins joined at the sacrum and lower back with partially shared spinal cords as well as lower intestinal and genitourinary tracts. They were deemed candidates for separation at 6 to 8 months of age. The patients' legal guardian provided informed consent for publication of the study data.

Postnatal echocardiography of Twin A confirmed a large unrestrictive malalignment ventricular septal defect (VSD) and long segment hypoplasia of the aortic arch tapering to a $0.19 \mathrm{~cm}(z$ score, -2.9$)$ focal coarctation at the isthmus (Figure 1). There was a patent ductus arteriosus with bidirectional shunting. Twin A developed symptoms consistent with pulmonary overcirculation while receiving prostaglandin, so neonatal surgery was recommended. A multidisciplinary team determined that the option of palliating with coarctation repair and pulmonary artery bands would likely complicate extracardiac interventions. Therefore, the optimal repair was believed to be arch augmentation and VSD closure requiring bypass with deep hypothermic circulatory arrest (DHCA). To protect Twin B from arrhythmia or low output secondary to hypothermia during the procedure, extracorporeal membrane oxygenation (ECMO) would

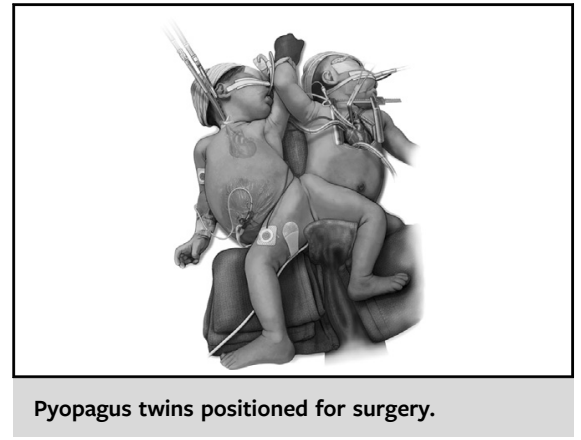

CENTRAL MESSAGE

First report of cardiac surgery utilizing cardiopulmonary bypass with deep hypothermic circulatory arrest in 1 neonate and extracorporeal membrane oxygenation support in the other unseparated, pyopagus conjoined twin.

See Commentaries on pages 303 and 305. be used. Additionally, Twin B would be cooled to $24^{\circ} \mathrm{C}$ to protect Twin A from being warmed while under DHCA.

Both neonates were under general anesthesia with monitoring, including cerebral near infrared spectroscopy and rectal temperature probes (Figure 2). A sternotomy was performed on Twin A and sutures were placed for aortobicaval cannulation. For Twin B, an incision was made over the right neck, and the carotid artery and jugular vein were controlled and cannulated for ECMO with a heater/cooler in line. Twin A was heparinized and cannulated for bypass. After patent ductus arteriosus ligation, Twin A was cooled to $18^{\circ} \mathrm{C}$ and Twin $\mathrm{B}$ was placed on ECMO and cooled to $24^{\circ} \mathrm{C}$. After Twin B was cooled, circulatory arrest was commenced for Twin A. Homograft patch aortoplasty was performed. Bypass was resumed and the VSD was patch closed during rewarming of both patients. The infants were simultaneously separated from bypass and ECMO (Figure 3). Transesophageal echocardiography demonstrated no residual VSD and an unobstructed arch with no gradient. The cannulas were removed from both infants. 


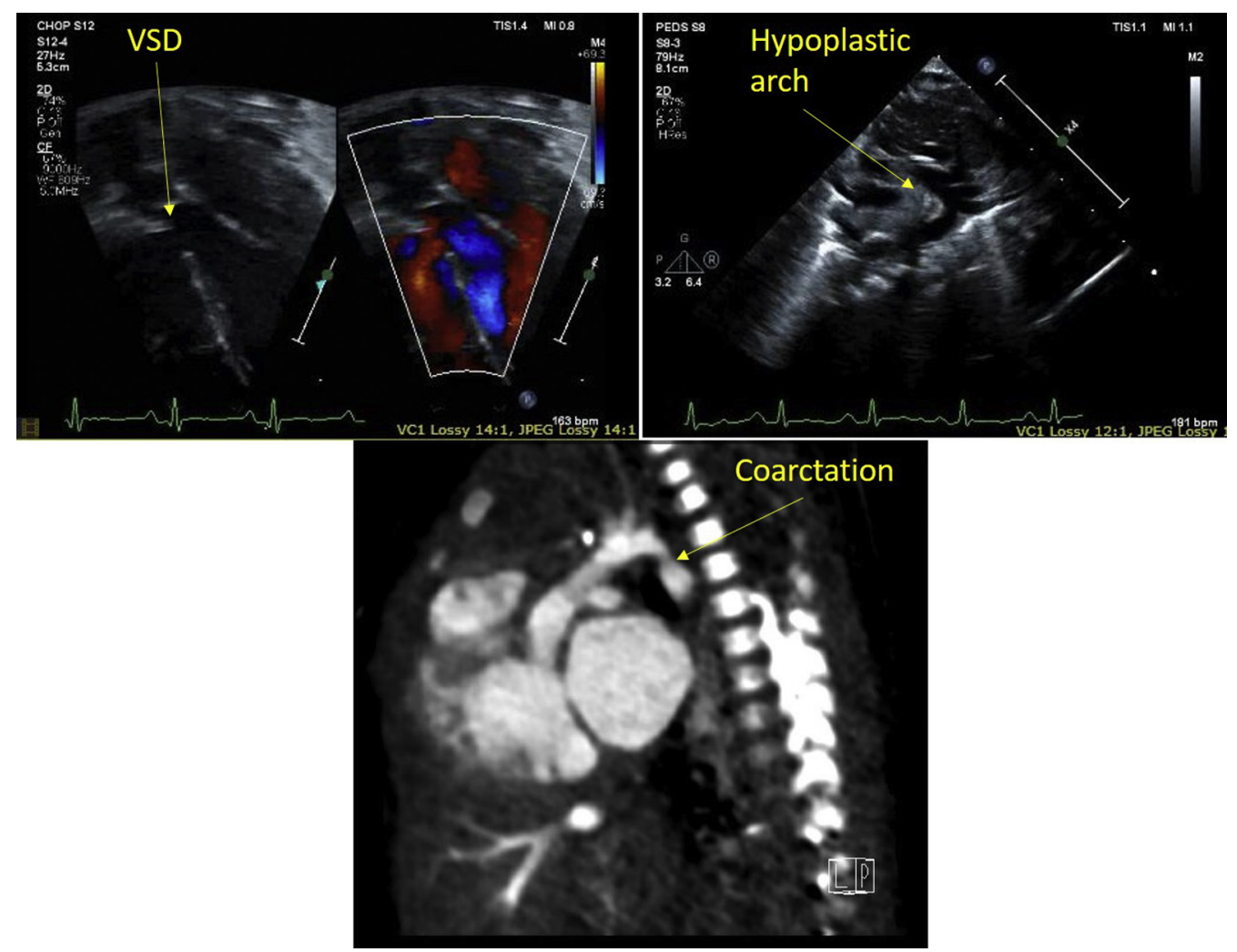

FIGURE 1. Preoperative imaging of Twin A. VSD, Ventricular septal defect.

For Twin A, the bypass, crossclamp, and DHCA times were 85, 54, and 25 minutes, respectively. The ECMO time for Twin B was 107 minutes. Near infrared spectroscopy for both neonates remained at baseline during the case. Both infants had normal neurologic exams for age and were transferred out of the cardiac intensive care unit on postoperative day 7 .

\section{DISCUSSION}

In the United States, associated congenital cardiac anomalies are seen in $36 \%$ of conjoined twins with $5 \%$ requiring major cardiac operation. ${ }^{4} \mathrm{~A}$ previous report describes the use of cardiopulmonary bypass without hypothermia or arrest to perform a palliative shunt on 1 infant while maintaining normal circulation on the conjoined twin. ${ }^{1}$ Those authors described differing arterial blood pressure, arterial oxygen saturations, and cerebral oximetry readings between the twins.

A major concern in this case was management of DHCA required for arch reconstruction in a conjoined neonate with an unknown amount of shared circulation. There was concern that cardioplegia delivery and cooling of Twin A could adversely affect Twin B. A separate issue was that Twin B had no anatomic or functional cardiac issues, but being conjoined is thus exposed to the consequences of the health of her sibling. The risk minimization strategy for her needs to account for the total set of risks (A and B).

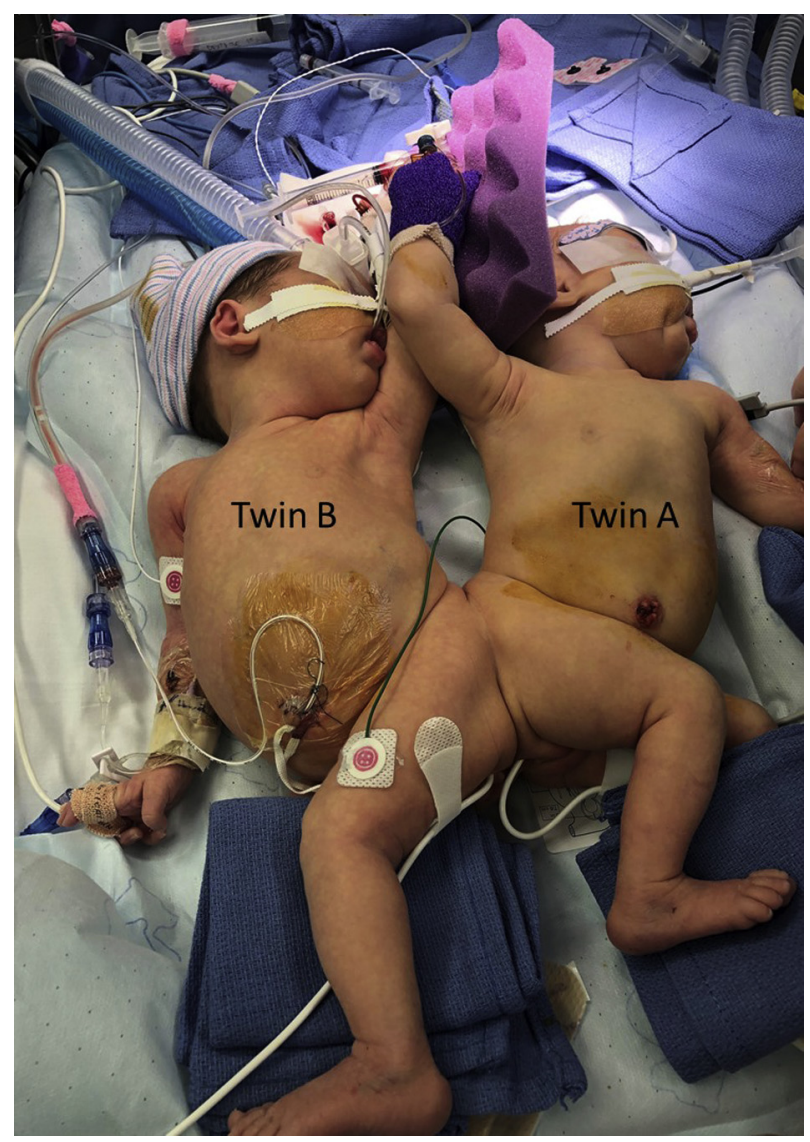

FIGURE 2. Photo of twins positioned for surgery.

JTCVS Techniques • Volume 3, Number C 


\section{Operative Timeline}

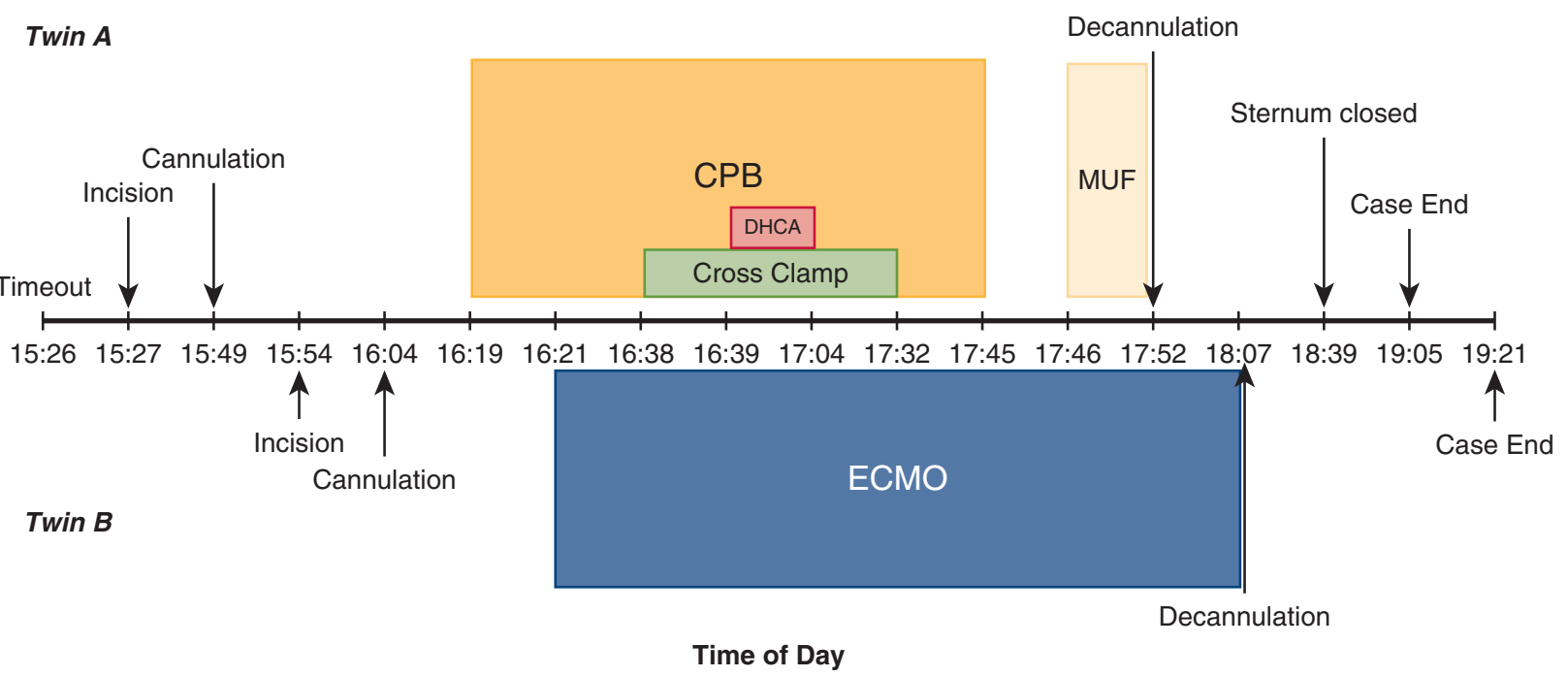

FIGURE 3. Operative timeline. $C P B$, Cardiopulmonary bypass; $D H C A$, deep hypothermic circulatory arrest; $M U F$, modified ultrafiltration; $E C M O$, extracorporeal membrane oxygenation.

Administration of a paralytic agent to Twin A during anesthetic induction caused apnea in Twin B. In contrast, Twin B maintained normal cardiac electrical activity despite cardioplegia administration to Twin A. This confirmed our belief that the 2 shared an unpredictable, unknown amount of circulation. Also during DHCA, Twin A had significant blood return to the heart likely from the ECMO circuit of Twin B.

One could advocate doing the arch via left thoracotomy and placing a pulmonary artery band. However, representatives of the other involved disciplines desired to have her cardiac issues definitively treated to best position her for the multiple other operations required in the near future to prepare for separation. The surgery proved successful in achieving adequate end organ perfusion in both neonates without negative effects. This approach might be useful in other conjoined twins to allow preseparation repair of complex congenital cardiac defects.

\section{References}

1. Tirotta CF, Lagueruela R, Munro HM, Zahn EM, Lopez L, Burke RP. Anesthetic management of conjoined twins presenting for palliative open-heart surgery. Anesth Analg. 2005;101:44-7.

2. Chen G, Jia B, Zhang WB. Successful surgical repair of d-transposition of the great arteries in a separated conjoined twin. World J Pediatr. 2012;8: 371-3.

3. Cordoba RA, Juaneda E, Alday LE. Surgical ligation of a persistent arterial duct in one of conjoined thoracopagus twins prior to surgical separation. Cardiol Young. 1999;9:203-6.

4. Mutchinick OM, Luna-Muñoz L, Amar E, Bakker MK, Clementi M, Cocchi G, et al. Conjoined twins: a worldwide collaborative epidemiological study of the international clearinghouse for birth defects surveillance and research. Am J Med Genet C Semin Med Genet. 2011;157C:274-87. 